\title{
Opportunities and Challenges of Employing Heat-Pipes in Thermal Management of Electrical Machines
}

\author{
R. Wrobel, R. J. MGlen
}

\begin{abstract}
Thermal management of power electronics, electrical machines and drives has become one of the key enabling factors in delivering of the future high-specific-output solutions for low-/zero-emission electrified propulsion. This paper reviews heat-pipe technology in application to electrical machines with focus on opportunities and challenges associated with successful deployment of such heat transfer/removal approach. Although, the use of heat pipes in electrical machines has been explored by numerous authors over decades of research, continuous developments in the materials and manufacturing techniques have opened new design avenues, with the high-rate heat transfer, low-added-weight, high-level of integration and reliability being some of the benefits of heat-pipe enabled cooling solutions. In this paper, underpinning fundamentals of the heat pipes construction and operation are discussed, with emphasis on the new/emerging solutions allowing for a more measured integration of heat-pipe-based or assisted thermal management systems in electrical machines. A number of examples of employing heat pipes in commercial and research applications are provided from the available literature together with the authors forecasts of the possible future technology advancement.
\end{abstract}

Index Terms-- Electrical machines, heat pipes, heat transfer, thermal management, additive manufacturing

\section{INTRODUCTION}

$\mathrm{T}$ HE modern day heat pipe (HP) technology has been developing well over a century, with the Perkins tube being its direct predecessor, 1831 [1]. The initial single-cycle tube/HP was later developed into two-phase-system, 1836, with the early applications being the locomotive boilers and fire box super-heaters [1]. HPs have found numerous applications, with the generic, functional/application groups including separation of heat source and heat sink, temperature flattening or isothermalisation, heat flux transformation, temperature control, thermal diodes and thermal switches [1], [2]. More specifically, HPs are commonly used in energy storage and preservation systems, nuclear reactors, air conditioning and cooling systems, chemical reactors, data centres, aircraft and spacecraft applications, vehicle and consumer electronics applications amongst others.

In the context of power electronics, electrical machines and drives (PEMD), thermal management of the electronic/power

This work was supported in by the Engineering and Physical Sciences Research Council UK (Future Electrical Machines Manufacturing Hub, $\mathrm{EP} / \mathrm{S} 018034 / 1)$.

R. Wrobel is with Newcastle University, School of Engineering, Merz Court, Newcastle upon Tyne, NE1 7RU, UK (e-mail: Rafal.Wrobel@newcastle.ac.uk). electronics has had considerable attention within several commercial applications [1]. In the majority cases, design considerations for the HP-based heat removal from power electronics are constrained to a good understanding of both the heat sources (power losses) and heat sink (heat removal routes). In contrast, electrical machines are more demanding as the additional power losses potentially introduced by the HP cooling system and mechanical considerations for the rotating parts need to be accounted for. The history of application of HPs in thermal management of electrical machines spans several decades and fits within the temperature flattening and control functional group, with numerous research papers, reports and patents documenting the technology evolution [1]-[39]. When reviewing the literature, it is evident that almost all possible/generic concepts of employing HPs in thermal management of electrical machines, both for the stator and rotor subassemblies have been previously considered [11], [15], [16]. Some of the concepts include HP rotor shaft cooling, HP stator or winding cooling, HPs as a squirrel cage and cooling feature for an induction machine (IM), among others [16].

The consecutive sections of this review paper discuss underpinning fundamentals of the HPs construction and operation, with the main focus being placed on wicked HPs as opposed to thermosyphons. Also, new HP solutions, enabled by current developments in the materials and manufacturing techniques, like polymers, ceramics and additive manufacturing (AM), are explored. Several examples illustrating commercial and research implementations of HPs in PEMD, are presented. Here, the emphasis is on electrical machines with HP-enhanced or HP based heat removal approaches. The authors forecasts on how the HP-enabled thermal management of electrical machines might evolve are provided in final remarks to the paper.

\section{HP TECHNOLOGY}

There are several types of HPs specifically developed to address particular functional/application design targets [1]. Some of the HP solutions/technologies include, variable conductance HPs, thermal diodes, pulsating HPs, loop HPs,

R. J. M ${ }^{\mathrm{c}}$ Glen is with Aavid, Thermal Division of Boyd Corporation, 12, Wansbeck Business Park, Ashington, Northumberland, NE63 8QW, UK (email: Ryan.McGlen@boydcorp.com). 


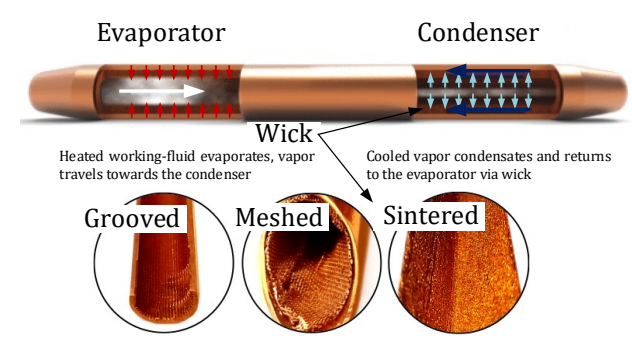

Fig. 1. Schematic representation of a Copper-Water HP together with alternative wick constructions

rotating HPs, and electro- and magneto-hydrodynamic HPs [1] among others. In this review more conventional, low-cost wicked HPs are discussed, as these seems to be preferred choice when considering PEMD applications.

\section{A. Principles of Operation}

Fig. 1 shows an example of conventional, wicked HP. The HP body consists of a sealed container, in which a wick structure is placed on the inner radius of the pipe wall. The wick acts as a capillary pump, which returns the condensate to the evaporator section of the HP. There are several types of wicks available, which provide different performance and cost measures. E.g. grooved HPs offer the lowest cost and high mass flow, but are not ideal for liquid return against gravity, whereas sintered HPs have the highest cost and good pumping capability, but with reduced power transport [1], [2]. The meshed HPs provide a compromise between the grooved and sintered HP variants. A typical Copper-Water HP with sintered wick is fabricated in two stages. The first stage is associated with construction of the wick. This usually involves inserting a cylindrical mandrel into a Copper pipe and then pouring powdered material, which later is sintered and bonds to the pipe wall by an appropriate sintering process. After sintering, the mandrel is removed, and the powdered material forms a porous annulus body, sintered wick. The second stage (charging and venting) involves removal of air from the HP, introduction of a working fluid to saturate the wick and finally sealing the HP container.

When heat is introduced to the evaporator section of the HP, liquid phase working fluid within the evaporator wick, evaporates. As the vapor flows into the adiabatic section of the heat pipe, a pressure drop occurs that enables acceleration of the vapor, creating a high mass flow rate of the working fluid to the condenser region, which due to condensation of the vapor, is at a lower pressure enabling fluid flow. The condensate is then pumped back to the evaporator due to the capillary-force, which is generated within the capillary structure within the wick. The phase-change phenomena employed in HPs allows to achieve very high values of equivalent thermal conductivity, typically from $5,000 \mathrm{~W} / \mathrm{m}$. $K$ to $100,000 \mathrm{~W} / \mathrm{m} \cdot K$, as compared with pure Copper, $387 \mathrm{~W} / \mathrm{m} \cdot K$ [36]. This value depends upon the mechanisms used to add heat at the evaporator, and remove it at the condenser, of course, where high conduction and convection thermal resistances may exist. HPs are well suited for transferring heat over long distances with a low temperature drop, providing an approximately isothermal surface for temperature flattening or controlling. This is very attractive in the context of thermal management of electrical machines, where the generated heat needs to be removed from intricate composite structures, e.g. winding body or rotor assembly.

\section{B. Design and Operating Limits}

The fundamental/design operating limits of wicked HPs are governed by several physical effects [1]. Fig. 2 presents schematically HP performance (axial heat flux) versus temperature together with the operating limits. The first in Fig. 2, viscous limit (vapor limit) is associated with HP operating below its normal temperature range, e.g. during start-up from frozen state. In such case, the vapor pressure is relatively small. Consequently, the viscous forces dominate motion of the vapor along the HP length. The sonic limit is related to flow speed, at which vapor leaves the evaporator. When the vapor flow reaches sonic velocity, the flow along the HP is choked. This is caused by too much input heat at lower operating temperatures (high temperature gradient between evaporator and condenser). The effect is self-correcting and is usually present at HP start-up. The next operating limit in Fig. 2 is also related to high flow velocity of the vapor, entrainment limit. Here, droplets of liquid can be torn from the wick structure and entrained into the vapor flowing towards the condenser section. In a severe case the evaporator can be starved from the working liquid, also known as HP 'dry out'. The capillary limit (hydrodynamic limit) is related to the wick structure and its ability to provide sufficient capillary pumping. If the maximum capillary pressure at the wick is lower than the sum of gravitational, liquid and vapor pressure drop, the HP/evaporator dries out. The last operating limit in Fig. 2 is associated with radial heat flux as opposed to discussed earlier axial heat flux. The boiling limit occurs when the radial heat flux in the evaporator is too high. This causes boiling of the liquid and in severe cases leads to HP 'dry out'.

As outlined in the previous section, the HP performance is affected by the performance limits. In particular interest for motor machine applications, the capillary limit is affected by HPs orientation, e.g. vertical orientation of HP with the condenser located below evaporator might be challenging for some HP topologies as the wick structure needs to assure

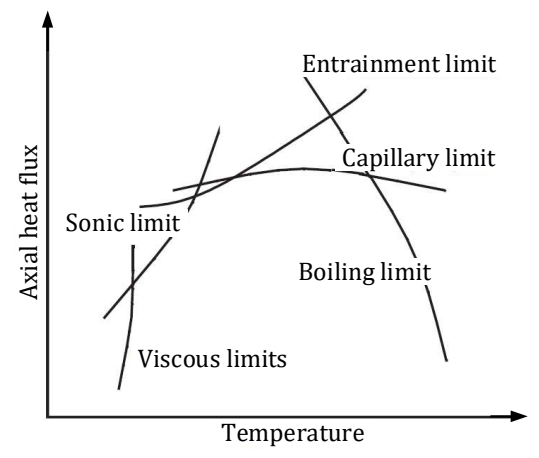

Fig. 2. HP heat transport capability versus temperature together with operatizing limits - David Reay \& Associates, Aavid, Thermal Division of Boyd Corp. and Heriot-Watt University [1] 
sufficient capillary-force/-pumping against the gravity in such case. Also, high-G acceleration and/or low gravity environment are the other in-application operating limits, which frequently need to be accounted for when considering space, aerospace and automotive applications.

\section{Construction and Material Compatibility}

When designing HP for a specific application, selecting appropriate materials is prerequisite to reliable HP operation. In general, a combination of the working fluid and material for HP determines its operating temperature range and overall heat transfer capability. Table I lists commonly used material combinations with temperate range relevant for PEMD applications. However, in general, the operating temperate limits of HPs are significantly broader, with the lower end bounds from $-271^{\circ} \mathrm{C}$ to $-269^{\circ} \mathrm{C}$ for Stainless/Steel /Titanium-Helium, and the upper limits from $+1100^{\circ} \mathrm{C}$ to $+1825^{\circ} \mathrm{C}$ for Tungsten/Niobium/Molybdenum-Lithium. Note that some materials are inherently incompatible, which might lead to internal non-condensable gas generation, corrosion and material transport, and consequently are not recommended for constructing reliable HP solutions. An example here is Aluminium-Water. Further to the material compatibility issues, the use of specific materials may impose manufacturing changes, which prevent reliable fabrication of specific wick structures, for example sintered Aluminium wicks.

Fig. 3 presents examples of practical implementation of HPs in thermal management of power electronics. A typical arrangement of HP enabled heat transport between the heat source and heat sink is shown in Fig. 3a). Here, however, the heat source and heat sink are electrically isolated (several $\mathrm{kV}$ ). This particular heat removal system was developed for TABLE I

HP MATERIAL COMPATIBILITY AND OPERATING TEMPERATURE RANGE

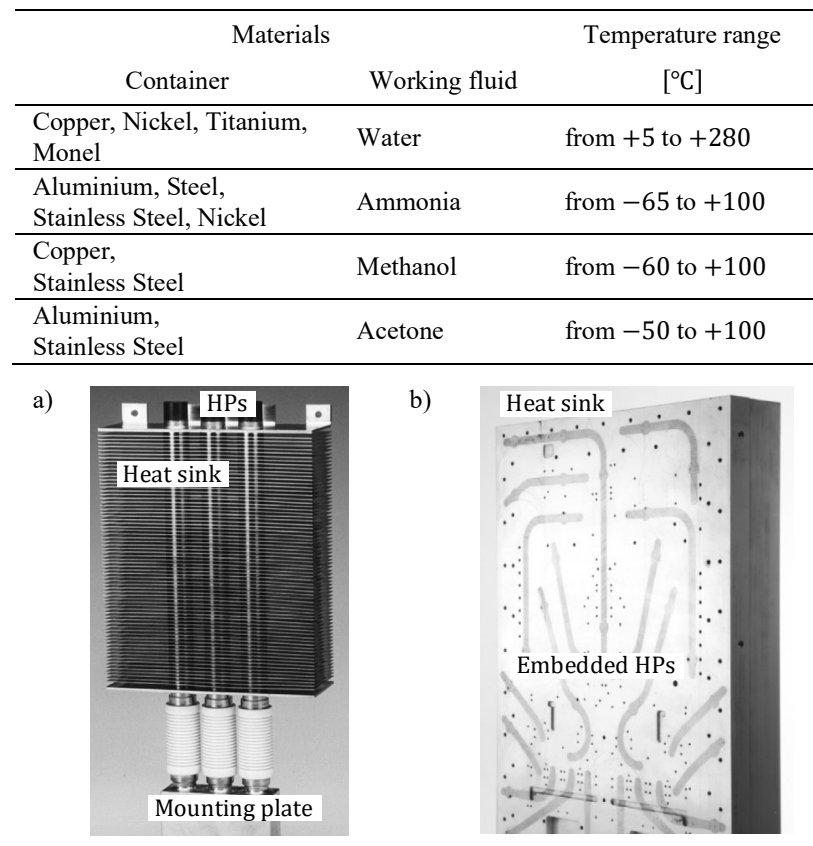

Fig. 3. Examples of HP-based power electronics thermal management systems, a) electrically isolated tubular HPs, b) heat sink with embedded HPs - Aavid, Thermal Division of Boyd Corp. [1]

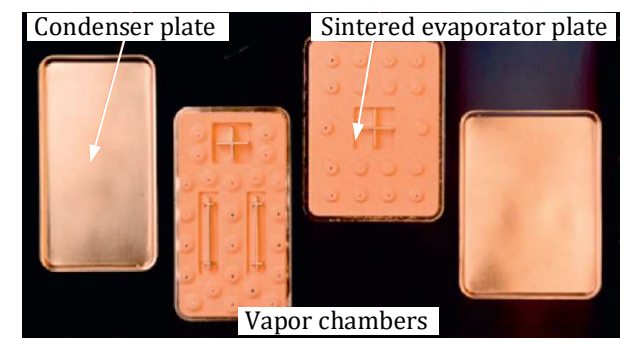

Fig. 4. Example of flat HP (vapor chamber) for cooling of power electronic - Aavid, Thermal Division of Boyd Corp. [1]

highspeed trains [1]. Fig. 3b) shows a heat sink with integrated HPs to assure even temperature distribution of power electronics devices. A set of Copper-Water HPs was embedded within the heat sink body by appropriate soldering and flattening of the HPs. In this application, the use of HP allowed to reduce size of the thermal management system by $45 \%$ as compared with conventional heat sink solution. The developed heat sink allows for $1.5 \mathrm{~kW}$ of power losses to be removed with the maximum temperature of power electronics switches below $120^{\circ} \mathrm{C}$.

When referring to HPs, frequently a pipe-like geometrical structures come to mind. However, modern HP solutions are not limited to this specific mechanical space envelope. Fig. 4 presents an example of flat HP (vapor chamber) developed for cooling of power electronics. Here, the internal structure of the HP was designed to allow for a free flow of the vapor. Interestingly, a custom wick with varied thickness was used in this design to target high heat flux regions. However, fabrication of more geometrically/functionally complex HP based solutions for thermal management of PEMD might be challenging and/or cost ineffective when considering the conventional materials and manufacturing techniques. In that context, there has been considerable interest in employing new materials like polymers [5], ceramics [7], [8], metallic alloys and techniques, e.g. additive manufacturing AM [6], [29][34], [37]-[39] for fabrication of integrated two-phase heat removal systems. Several examples of employing AM in construction HPs have been selected here, as this fastdeveloping manufacturing technique has had the most attention [35]. European patent granted to Aavid, is believed to be the first patent on AM of HPs with integrated capillary wicks [37].

Fig. 5 presents examples of Aluminium alloy (A1Si12)Ammonia HPs with hybrid sintered wick structures, manufacture of which was enabled using AM with selected laser melting (SLM). Here, the hybrid wick design allows for a)
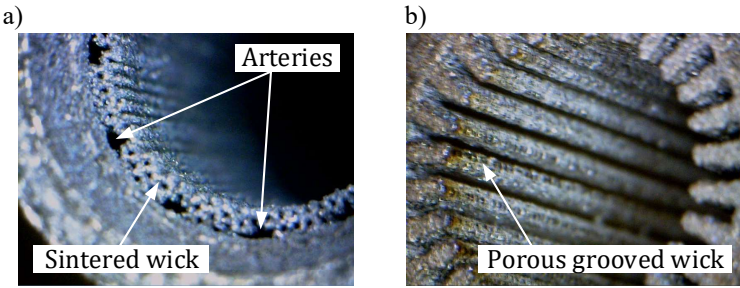

Fig. 5. AM Aluminium-Ammonia HPs with sintered hybrid wick structure, a) arterial wick, porous grooved wick (HP: $\emptyset 14 \mathrm{~mm}$ and $70 \mathrm{~mm}$ length) - Aavid, Thermal Division of Boyd Corp. [37], [38] 


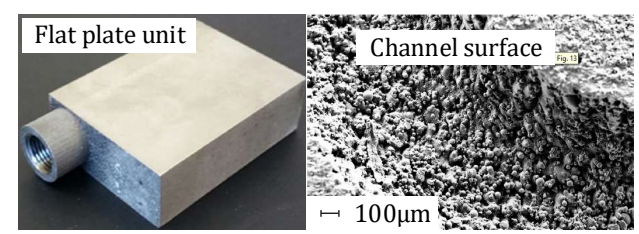

Fig. 6. AM multi-layered flat-plate oscillating HP together with close up (scanning electron microscopy (SEM) image) on the HP channel Mississippi State University, Texas A\&M University [29]

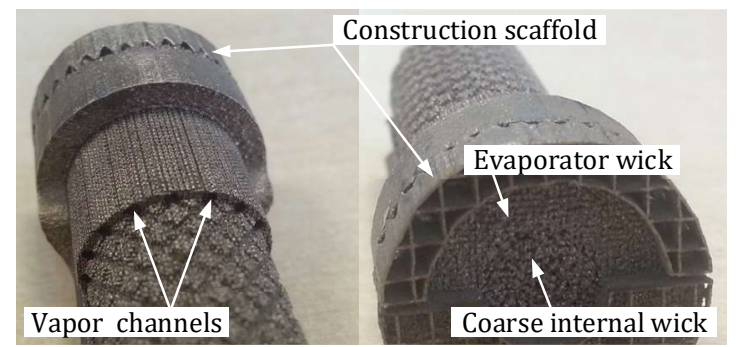

Fig. 7. AM wick sample for loop HP together with close up on varied density wick structure - Aavid, Thermal Division of Boyd Corp. [37], [38]

reduced pressure drop along the wick structure while maintaining high capillary pumping capability [37], [38]. Consequently, a considerable improvement in HP heat transport capability has been achieved. Note that fabrication of similar sintered Aluminium wicks would be very challenging when using conventional fabrication techniques.

Fig. 6 present AM multi-layered flat-plate oscillating HP capable of operating in different orientations, i.e. work against gravity. Here, the authors used SLM together with Titanium alloy (Ti6Al4V). The complete flat-plate uses HPLC-grade water (high purity water) as a working fluid. This early technology demonstrator showed 500\% improvement in equivalent thermal conductivity as compared with a solid/conventional plate [29]. The characteristic imperfections of the flat-pale channels shown in Fig. 5, i.e. partially melted or sintered particles of Titanium alloy are envisaged as a secondary capillary structure, which might be particularly beneficial during start-up and for pressure balancing between the individual channels [29].

The use of AM has been frequently associated with low volume and higher overall production cost. This trend has been changing recently [37]. Fig. 7 shows a proof of concept AM loop heat pipe evaporator body. Here the component was AM from Titanium (Ti6Al4V) powder as a single part, that incorporates a fine pore size primary wick, solid external

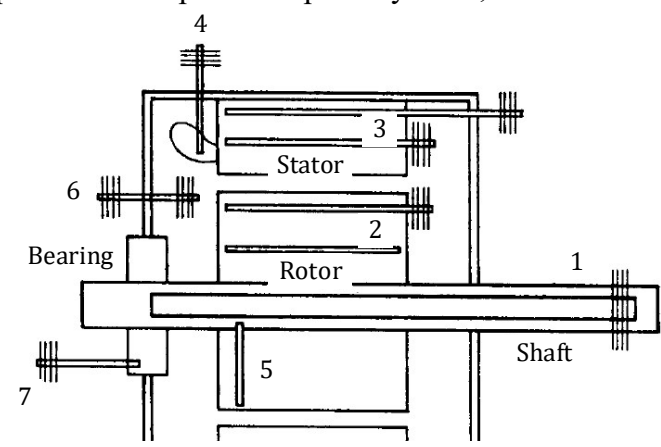

Fig. 8. Application of HPs in thermal management of electrical machines - ERA Technology [3] tube wall and solid internal bulkhead walls that minimise reverse flow of vapor. The bore of the primary wick incorporates a graded, larger pore-size secondary wick, that demonstrates the potential evolution and integration of the secondary wick. The primary wick incorporates internal vapor flow passages, which provide full coverage of the tube inside diameter with wick structure, that potentially gives a performance benefit over conventionally machined primary wicks.

\section{HPS IN ELECTRICAL MACHINES}

As previously highlighted, the use HPs in electrical machines has been explored with varied intensity for several decades. E.g. Siemens introduced a hollow shaft with rotating heat pipes in 1970 [27]. Since then a considerable effort has been made to evaluate alternative HP-based thermal management concepts. Fig. 8 schematically shows possible arrangements of HPs for removing heat from various subregions of an electrical machine: 1 - shaft, 2 and 5 - rotor (axial and radial heat transfer), 3 - stator-winding active length, 4 - end-winding, 6 - end region cavity and 7 - bearing assembly [3]. Although Fig. 8 suggests that HPs were predominantly envisaged for heat removal, there were also, attempts of using HP in a multifunctional manner, e.g. HPs as an electrical conductor and heat transfer feature for a squirrel cage/IM application [25], [27]. The early research, late 80's, was focused on IMs showing that HP-based thermal management offers approximately $20 \%$ increase in power density (IMs power range of $75 \mathrm{~kW}$ to $150 \mathrm{~kW}$ ) [27]. There were also examples of commercial deployment of HPs in electrical machines, FANUC ac spindle motor [27]. Despite of the clear performance benefits, HP technology in thermal management of electrical machines was found to be commercially unfeasible/unsuccessful at that time due to cost and long-term reliability concerns [27].

However, both issues have been addressed since then to some degree using modern volume manufacturing processes and quality control. Also, the use of new materials, and manufacturing techniques opens interesting design avenues for a more effective integration of HPs in electrical machines. As thermal management of electrical machines has been gaining increased attention due to the continuous drive towards high-specific-output solutions, it is worth revisiting the HP-based heat removal in the context of new technological/commercial landscape. The next section of the paper provides a spectrum of examples (with focus on the most recent developments) of employing HPs in thermal management of electrical machines.

\section{A. Examples of HP-Based Thermal Management of Electrical Machines}

Fig. 9 shows an early example of employing HPs in thermal management of an IM $(7.5 \mathrm{~kW}, 12,000 \mathrm{rpm})$ [25]. Both the stator and rotor include screen mesh wicked Copper-Water HPs with a finned heat exchangers (HEs) allowing the generated heat to be dissipated within the motor enclosure. Here, the internal air-flow is generated by rotation of the rotor with HPs. The stator HPs are buried in the winding/centre of 
the slot and then impregnated to provide good thermal contact between the winding body and HPs. The rotor HP form a squirrel-cage. The prototype IM was extensively tested confirming all initial design targets with focus placed on widerange of operating speed (1 to 7 ). The authors suggested that the proposed/advanced thermal management system is particularly well- suited for high-power-density, wide-range of operating speeds electrical machines.

A more recent example of using HPs for an effective heat removal in electrical machines is presented in Fig. 10. In contrast to the previous example, here, the authors use HPs to enhance heat removal from the winding end region of a permanent magnet (PM) motor (53 $\mathrm{kW}, 4,000 \mathrm{rpm})$. A set of hybrid (grooved/sintered) Copper-Water HPs was mounted in the motor end-windings prior to encapsulation of the entire winding body. Again, the winding encapsulation provides a good thermal contact, which consequently leads to improved heat transfer across from the winding body to liquid-cooled motor housing/HPs. Note that the liquid-cooled housing provides here the primary heat removal path, Fig. 10. The authors demonstrated that HP-enhanced thermal management system allowed to reduce the end-wind hot-spot temperature by more than $20^{\circ} \mathrm{C}$ and elongate the duration of the transient overload by $60 \%$. In addition, a more uniform temperature distribution along the winding body was achieved, which is particularly important when considering reliability of the winding electrical insulation system [9].

Fig. 11 shows an experimental setup for assessing thermal behaviour of a stator-winding assembly with optional HP-

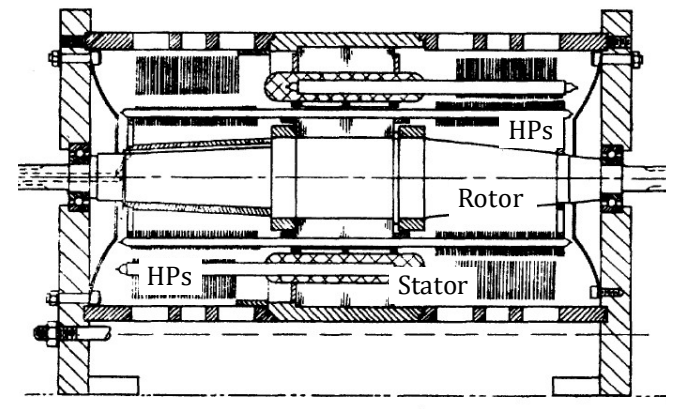

Fig. 9. Cross-section of PM IM with HP-based thermal management of both stator and rotor sub-regions (HP: $\varnothing 7 \mathrm{~mm}$ and $90 \mathrm{~mm}$ length) General Electric Company [25]

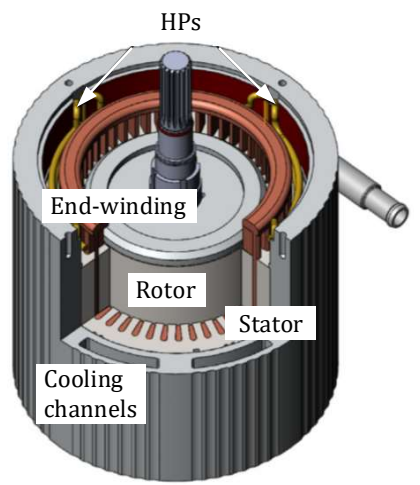

Fig. 10. Outline of PM motor with end-winding HP cooling system (HP: $\emptyset 6 \mathrm{~mm}$ ) - South China University of Technology, City University of Hong Kong [9]

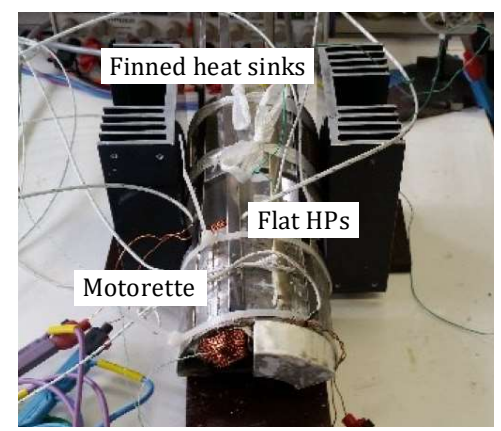

Fig. 11. Experimental setup for motorette thermal characterisation of alternative HP-based heat removal concepts (HP: $9 \mathrm{~mm} \times 1 \mathrm{~mm}$ and $350 \mathrm{~mm}$ length) - University of Erlangen-Nuremberg [28]

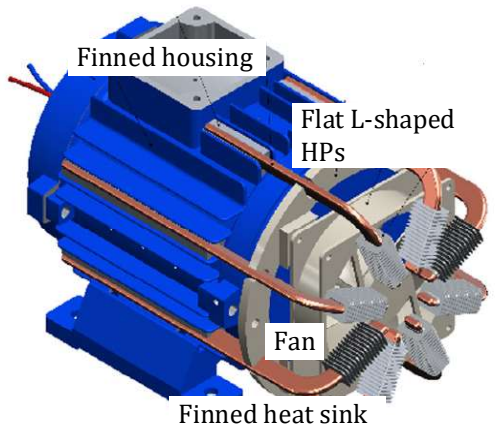

Fig. 12. Finned motor housing with L-shaped HP and fan arrangement for improved heat removal (HP: $10.5 \mathrm{~mm} \times 4 \mathrm{~mm}$ and $200 \mathrm{~mm}$ length) University of Indonesia [15]

based heat removal concepts. Here, the authors used a motorette (sector of a stator-winding assembly) representative of a flux-switching PM motor. A set of flat, meshed CopperWater HPs was used in circumferential and axial orientation showing that later one is more effective in removing heat, in the analysed case. A significant $60 \%$ increase in current density for HP enabled thermal management system was reported. Also, a more flexible arrangement for heat sinking is suggested by the authors as one the potential benefits of using HPs in thermal management of electrical machines.

The next example, Fig. 12, presents a HP-based thermal management system to enhance heat removal from a naturally cooled machine $(400 \mathrm{~W})$. Here, the authors used a family of L-shaped sintered Copper-Water HPs to enhance heat removal from the machine's finned housing. Note that such housing construction is frequently accompanied with the rotor-shaft or independently driven fan arrangement to provide sufficient heat removal. This however produces a considerable increase of the machine volume. In Fig. 12, the motor housing is interfaced with finned HPs and a small fan. The generated heat is transported from the motor housing/fins to a more convenient location, where a more measured heat removal can be introduced [15]. The experimental findings show over $44 \%$ improvement in heat removal for the proposed system.

Fig. 13 shows a set of winding coils with HPs developed for a directly driven multistage axial-flux wind generator (25kW, 100rpm) [22]. Here, the authors investigated alternative HPs arrangements in the winding body to provide improved heat removal from such compact/difficult to 


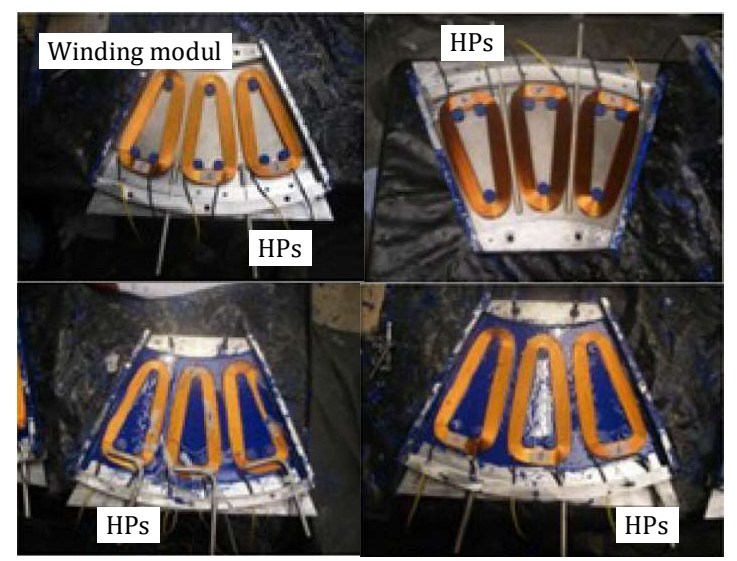

Fig. 13. Segments of a winding incorporating HPs for enhanced heat removal from an axial-flux generator - University of Edinburgh, Motor Design Ltd., Middle Eastern Technical University, University of Strathclyde, Fountain Design Ltd. [22]

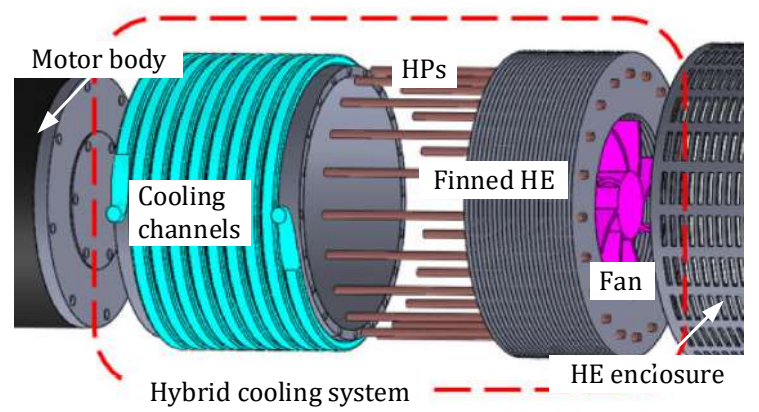

Fig. 14. Hybrid cooling concept utilising HP-based air-cooled HE Clemson University, U.S. Army Tank Automotive Research, Development and Engineering Center (TARDEC) [23]

effectively cool structure. The experimental results showed that L-shaped HPs located at the winding outer diameter offers the best heat removal, with $20 \%$ winding hot-spot temperature reduction as compared to winding build with no HPs in place. That improvement translated to $11 \%$ increase in the generator's output power [22].

The last example, Fig. 14, presents theoretical study of a hybrid cooling system utilising HPs [23]. The proposed thermal management concept has been developed to reduce energy consumption required to remove generated heat from the analysed traction motor. The proposed system uses both conventional liquid-cooled housing and HPs integrated with fan cooled HE. Such arrangement allows to tailor heat removal required for healthy operation of the motor as a function of driving cycle/operating regime. The theoretical findings showed clear energy consumption benefits of the hybrid solution as compared with more common (liquid-cooled housing) alternative [23].

\section{CONCLUSIONS AND OBSERVATIONS}

This review paper has introduced HP technology in the context of thermal management for PEMD. Working fundamentals of two-phase wick HPs have been briefly discussed together with selected design and operating limits. Several examples of common applications of HP-based heat removal systems have been presented and discussed. It has been shown that HP technology is very versatile and has been successfully used across variety of applications for several decades.

Interestingly, the use of HP in electrical machines has also been extensively explored. Although, the commercial application of HPs in electrical machines have been less obvious $\backslash$ successful, the potential performance benefits are very clear and desirable when considering the high-specific output PEMD solutions. It seems that the research and development carried out in the 70's and 80's were more comprehensive as compared with the recent activates. Some of the concerns related to commercial, compatibility and reliability aspects of deploying HP technology in electrical machines were addressed by the use of modern manufacturing techniques and quality check processes. E.g. HPs for satellite applications are design to continuously operate for 20 years.

The most recent work exploring the use of HPs in electrical machines is predominantly based on off the shelf CopperWater HP solutions, with various wick structures. Such HPs are relatively inexpensive, but impose several thermal and electromagnetic compatibility issues, subject to a specific thermal management system architecture. E.g., heat removal directly from the winding assembly seems very attractive, however an additional power loss generated in HP body requires careful considerations. Also, the overall heat transport capability of a specific HP is limited, which also need to be accounted for when designing HP-based thermal management systems for electrical machines. Perhaps, the use of modern manufacturing techniques like AM and materials will allow for a more measured/effective heat removal solutions employing HPs. Several examples of employing AM discussed in this review paper have already shown clear performance and cost benefits. It is the authors opinion that this technology evolution will enable new highly effective, compact/integrated HP-based solutions for thermal management of PEMD, e.g. integrated motor drives for automotive and aerospace propulsion/on-board power generation. The use of more conventional HP technology has also a great potential to be successfully implemented as a more immediate and commercially viable solution.

\section{ACKNOWLEDGMENT}

The authors wish to thank the Engineering and Physical Sciences Research Council (EPSRC) UK for supporting this research.

\section{REFERENCES}

[1] D. A. Reay, P. A. Kew, R. McGlen, 'Heat Pipes: Theory, Design and Applications,' Elsevier, 2013.

[2] A. Faghri, "Heat Pipes: Review Opportunities and Challenges," Frontiers in Heat Pipes, vol. 5, no. 1, pp. 1 - 48, 2014.

[3] M. Bradford, 'The Application of Heat Pipes to Cooling Rotating Electrical Machines,' IET International Conference on Electrical Machines and Drives, pp. 145 - 149, 1989.

[4] M. Popescu, D. A. Staton, A. Boglietti, A. Cavagnino, D. Hawkons, J. Goss, 'Modern Heat Extraction Systems for Power Traction Machines - A Review,' IEEE Transactions on Industry Applications, vol. 52, no. 3, pp. $2167-2175$, May/June 2016.

[5] C. Oshman, B. Shi, C. Li, R. Yang, Y. C. Lee, G. P. Peterson, V. M. Bright, "The Development of Polymer-Based Flat Heat Pipes," IEEE Journal of Microelectromechanical Systems, vol. 20, no. 2, pp. 410 417, April 2011. 
[6] D. Jafari, W. W. Wits, B. J. Geurts, "Metal 3D-Printed Wick Structures for Heat Pipe Application: Capillary Performance Analysis," Applied Thermal Engineering, Elsevier, vol. 143, pp. 403 - 414, July 2018.

[7] N. Hack, S. Unz, M. Beckmann, "Ceramic Heat Pipes for High Temperature Applications," Energy Procedia, Elsevier, vol. 120, pp. $140-148$, August 2017.

[8] P. Meisel, M. Jobst, W. Lippmann, A. Hurtado, "Design and Manufacture of Ceramic Heat Pipes for High Temperature Applications," Applied Thermal Engineering, vol. 75, pp. 692 - 699, January 2015.

[9] Y. Sun, S. Zhang, G. Chen, Y. Tang, F. Liang, "Experimental and Numerical Investigation of Novel Heat Pipe Based Cooling Strategy for Permanent Magnet Synchronous Motor," Applied Thermal Engineering, vol., pp. 1 - 10, January 2020.

[10] A. Tuysuz, F. Meyer, M. Steichen, C. Zwyssing, J. W. Kolar, "Advanced Cooling for High-Speed Electrical Machines," IEEE Transactions on Industry Applications, vol. 53, no. 3, pp. 2077 - 2087, May/June 2017.

[11] M. Bernagozzi, A. Gerogulas, I. Malavasi, N. Miche, M. Marengo, "A Novel Lumped Parameter Model for Loop Heat Pipes - Validation and Parametric Analysis," $15^{\text {th }}$ UK Heat Transfer Conference, pp. 1 -2, September 2017.

[12] M. P. Kukharskii, "Closed Evaporative Cooling of Rotating Electrical Machines," Journal of Engineering Physics, vol. 27, no. 3, pp. $446-$ 456, September 1974.

[13] N. Aprianingsih, A. Winarta, B. Ariantara, N. Putra, "Thermal Performance of Pulsating Heat Pipe on Electric Motor as Cooling Application," $3^{\text {rd }}$ International Tropical Renamable Energy Conference, pp. 1- 6, 2018.

[14] D. C. Deisenroth, M. Ohadi, "Thermal Management of High-Power Density Electric Motors for Electrification of Aviation and Beyond," Energies, MDPI, vol. 12, no. 19, pp. 1 - 18, September 2019.

[15] N. Putra, B. Ariantara, "Electric Motor Thermal Management System using L-Shaped flat Heat Pipes," Applied Thermal Engineering, Elsevier, vol. 127, pp. 1156 - 1163, February 2017

[16] M. Bradford, "The Application of Heat Pipes to Cooling Rotating Electrical Machines," $4^{\text {th }}$ International Conference on Electrical Machines and Drives, pp. 145 - 149, 1989.

[17] P. J. Marto, A. S. Wanniarachchi, "Heat Pipe Cooling of Large Electric Motors," Naval Postgraduate School Monterey CA, Progress Report NPS69-88-012PR, pp. 1 - 72, 1988.

[18] C. Tighe, C. Gerada, S. Pickering, "Assessment of Cooling Methods for Increased Power Density in Electrical Machines," XXII International Conference on Electrical Machines, pp. 1 - 7, September 2016;

[19] T. A. Jankowski, "Numerical and Experimental Investigations of a Rotating Heat Pipe," PhD thesis, The University of New Mexico, USA, May 2007.

[20] F. Wu, A. M. El-Refaie, "Investigation of an Additively-Manufactured Modular Permanent Magnet Machine for High Specific Power Design," IEEE Energy Conversion Congress and Exposition, pp. 777 - 784, 2019.

[21] R. Wrobel, A. Hussein, "A Feasibility Study of Additively Manufactured Heat Guides for Enhanced Heat Transfer in Electrical Machines," IEEE Transactions on Industry Applications, vol. 56, no. 1, pp. $205-2015$, January/February 2020.

[22] M. A. Mueller, J. Burchell, Y. C. Chong, O. Keysan, A. McDonald, M. Galbraith, E. J. P. Echenique Subiabre, "Improving the Thermal Performance of Rotary and Linear Air-Cored Permanent Magnet Machines for Direct Drive Wind and Wave Energy Applications,", IEEE Transactions on Energy Conversion, vol. 34, no. 2, pp. 773 - 781, June 2019.

[23] J. Huang, S. S. Naini, R. Miller, D. Rizzo, K. Sebeck, S. Shurin, J. Wagner, "A Hybrid Electric Vehicle Motor Cooling System - Design, Model, and Control," IEEE Transactions on Vehicular Technology, vol. 68 , no. 5, pp. 4465 - 4478, May 2019.

[24] B. J. Chalmers, J. Herman, "Induction-Motor Fan Drive with Unlaminated Rotor and Heat-Pipe Cooling," Proceedings of IEE, vol. 124, no. 5, pp. 449 - 454, May 1977.

[25] J. C. Corman, R. F. Edgar, M. H. McLaughlin, B. W. Merchant, R. E. Tompkins, "Heat Pipe Cooled Induction Motor," IEEE Transactions on Power Apparatus and Systems, vol. PAS-93, no. 4, pp. 1069 - 1075, July 1974.

[26] A. La Rocca, Z. Xu, P. Arumugam, S. J. Pickering, C. N. Eastwick, C. Gerada, S. Bozhko, "Thermal Management of a High Speed Permanent
Magnet Machine for an Aeroengine," XXII In International Conference on Electrical Machines, pp. 1 - 6, September 2016;

[27] G. O. Immel, "The Study of a Rotating-Heat-Pipe-Cooled Electric Motor," MSc thesis, Naval Postgraduate School, Monterey, California, USA, December 1980

[28] A. Lindner, I. Hahn, "Practical Evaluation of a Passive Stator Cooling Concept without Thermal Stacking," IEEE Workshop on Electrical Machines Design, Control and Diagnosis (WEMDCD), pp. 132 - 139, April 2017.

[29] S. M. Thompson, Z. S. Aspin, N. Shamsaei, A. Elwany, L. Bian, "Additive Manufacturing of Heat Exchangers: A Case Study on a MultiLayered Ti-6Al-4V Oscillating Heat Pipe," Additive Manufacturing, Elsevier, vol. 8, pp. 163 - 174, September 2015

[30] J. Esarte, J. M. Blanco, A. Bernardini, J. T. San-Jose, "Optimizing the Design of Two-Phase Cooling System Loop Heat Pipe: Wick Manufacturing with 3D Selective Laser Melting Printing Technique and Prototype Testing," Applied Thermal Engineering, Elsevier, vol. 111, pp. 407 - 419, January 2017.

[31] B. Richard, B. Anderson, C.-H. Chen, J. Crawmer, M. Augustine, "Development of a 3D Printed Loop Heat Pipe," $49^{\text {th }}$ International Conference on Environmental Systems, pp. 1 - 11, July 2019.

[32] M. T. Ababneh, C. Tarau, W. G. Anderson, "3D Printed Thermal Management System for the Next Generation of Gallium Nitride-Based Solid-State Amplifiers," $49^{\text {th }}$ International Conference on Environmental Systems, pp. 1 - 11, July 2019.

[33] K. K. Bodla, J. Y. Murthy, S. V. Garimella, "Evaporation Analysis in Sintered Microstructures," International Journal of Heat and Mass Transfer, Elsevier, vol. 61, pp. 729 - 741, June 2013.

[34] F. Wu, A. M. El-Refaie, "Investigation of an Additively-Manufactured Modular Permanent Magnet Machine for High Specific Power Design," IEEE Energy Conversion Congress and Exposition (ECCE), pp. $777-$ 784, September/October 2019.

[35] R. Wrobel, B. Mecrow, "A Comprehensive Review of Additive Manufacturing in Construction of Electrical Machines," IEEE Transaction on Energy Conversion, vol. 35, no. 2, pp. 1054 -1064, June 2020.

[36] Peterson, G.P., An Introduction to Heat Pipes: Modeling, Testing and Applications, John Wiley \& Sons, New York, US, (1994).

[37] European Patent No. 2715265, Aavid Thermacore Europe Ltd., Additive Manufactured Capillary Structures for Heat Pipe, 2018.

[38] M. Ameli, B. Agnew, P. S, Leung, B. Ng, C. J. Sutcliffe, J. Singh, R. $\mathrm{M}^{\mathrm{c}}$ Glen, "A Novel Method for Manufacturing Sintered Aluminium Heat Pipes (SAHP), Applied Thermal Engineering, Elsevier, vol. 52, pp. 498 - 504, January 2013.

[39] R. J. McGlen, C. J. Sutcliffe, "Additive Manufactured TitaniumAmmonia Heat Pipes for Thermal Management of Space Electronic Devices," $50^{\text {th }}$ International Conference on Environmental Systems, pp. $1-9$, July 2020.

\section{BIOGRAPHIES}

Rafal Wrobel (SMIEEE) received the M.Sc.Eng. degree from the Opole University of Technology, Opole, Poland, in 1998, the Ph.D. (hons) degree from the Lodz University of Technology, Lodz, Poland, in 2000, and the Habilitation degree from the Opole University of Technology, in 2013. He is currently a Senior Research Associate with Newcastle University, Newcastle upon Tyne, U.K. Rafal coordinates work of the Advanced Propulsion Centre (APC) U.K., Electrical Machines Spoke and the U.K. Magnetic Society. His research interest includes multidisciplinary design for the application of electrical machines, transformers, and wound passive components.

Ryan $\mathbf{M}^{\mathbf{c}}$ Glen received the B.Eng. (hons) degree from the University of Northumbria, Newcastle upon Tyne, U.K., in 2002 and the Ph.D. degree from Newcastle University, Newcastle upon Tyne, U.K in 2007. He is currently an Advanced Technology Manager with Aavid, Thermal Division of Boyd Corporation., where he leads a team of international research and development engineers focused on development of heat pipes and liquid cooling based thermal management systems for high-end electronics applications. His main research is on European Space Agency funded activities to development and qualify next generation thermal management systems for space flight. The main focus of Dr $\mathrm{M}^{\mathrm{c}}$ Glen work is on the development of additive manufactured heat pipes and in 2019, he was granted the first patent on additive manufacture heat pipe technology. 